\title{
Teachers' Interventions in Improving Numeracy Skills of Grade 7 Students in Baguio City National High School
}

\author{
Girlie D. Layug, Julie Pearl V. Velario and Josephine G. Capones \\ University of the Cordilleras, Philippines
}

\begin{abstract}
To address the Philippines' students' low numeracy levels, this study aims to determine and assess the interventions employed by teachers to enhance numeracy skills of grade 7 students at Baguio City National High School (BCNHS) with difficulty in mathematics and the effectiveness of these strategies. The study paper focuses on a quantitative method. It includes the use of a checklist anchored by a frequency distribution table for the multiple interventions utilized by grade 7 Math teachers. The effectiveness of the teachers' interventions will also be assessed using a Likert scale.

The result showed that the interventions applied by the teachers are as follows: Conference with parents and students, One - on - One Tutorial, Redo Activities with Low scores, Home Visitation, Provide Supplementary Materials and Activities, Lessen Items of Activities and Remedial Class. As a result, the effectiveness of these interventions range from moderately effective to highly effective, depending on the number of teachers who implement them. The interventions for enhancing students' numeracy skills are reported to be effective. It closes the gap between learners who are likely to fail Mathematics and those who are not. These interventions are the teacher's weapon in combating BCNHS's low numeracy rate among grade 7 students.
\end{abstract}

Keywords: Activities; Applied; Difficulty; Effectiveness; Utilized

\section{Introduction}

Mathematics literacy is a wide range of knowledge, understanding, and appreciation of what mathematics can accomplish rather than implying knowledge of various branches of mathematics or complex mathematical formulas. According to the Journal of Physics: Conference of Series, "mathematics literacy is the ability to understand and apply basic knowledge of mathematics in everyday life", which means, it entails comprehending and combining mathematical core concepts, terminologies, facts, and skills in response to the external situation's requirement of the real-world.

Mathematics has a vital part in the lives of students according to the George W. Bush Institute. It offers students job choices across many content areas of sciences, technologies, engineering and mathematics. It helps to promote critical thinking and address student difficulties. This makes them successful in the future in various ways.

However, despite different advantages of learning Mathematics, many, if not all, students find it extremely difficult to learn mathematics. This was supported by Garoof and Karukkan 


\section{$4^{\text {th }}$ International Conference on Advanced Research in Teaching and Education}

(2015), in their paper, Why High School Students Feel Mathematics Difficult? An Exploration of Affective Beliefs, which states that 88 percent of students in a 51-person random sample dislike mathematics due to difficulty in understanding the subject matter, and teacher or instructional related factors. This, on the other hand, contributes to poor level of mathematics literacy among students across the country.

Students from the Philippines are not exempted from this poor level of numerical competence. Infact, in 2018, the Programme for International Student Assessment (PISA) indicated that the Philippines placed second overall lowest in rank out of 79 participating nations worldwide. This merely implies that the students' mathematics abilities are really poor in the Philippines. Furthermore, students' attitude towards the subject, poor study habits or the excessive utilization of technologies might be the explanation for their continued underperformance in mathematics. In contrast, to halt the continued poor performance, the Philippine's Department of Education has been undertaking several interventions to increase the mathematical literacy of Filipino students who are having difficulty learning mathematics concepts.

Intervention as defined in the website achievement for all, is a selection of evidence-based teaching and learning processes to help students improve their learning. This entails choosing suitable interventions to assist a particular learner make purposeful changes in his or her learning. This was supported by Machera (2017), interventions according to him have benefits if administered properly, self-directing, cooperation and teamwork among students comprise some of the benefits. This is one of the many reasons why it is necessary to intervene. It will not only enable students to build their own emotional self, but it will also help them to know that their teachers are involved. This only proves that it is of significant relevance to select an effective and efficient mathematical intervention.

Academic interventions address the academic problems of a student (Matthew, 2019). Some of these implemented academic interventions in the Philippines were peer-tutoring/ assessment and self-assessment. Nevertheless, in spite of the efforts put by the teachers to implement interventions, students continued to exhibit downtrend performance in Mathematics. Thus, this paper aims to address this gap. Moreover, the study analyzes educators' various interventions to address the poor mathematical performance of students, as well as their efficiency in resolving learners' challenges in the development of basic mathematical abilities.

It was investigated that teachers at Baguio City National High School use a variety of interventions to assist struggling students in mathematics. These interventions have been implemented, but their effectiveness is contingent on the circumstances of the learners.

\section{Body of paper}

\subsection{Methods}

This part of the research discusses the research design, population and locale of the study, data gathering instruments, data gathering procedure and treatment of data.

\subsubsection{Research Design and Methodology}

Descriptive statistics was used in this research. It was utilized to identify the different interventions employed by the respondents to improve numeracy skills of grade 7 students and 


\section{$4^{\text {th }}$ International Conference on Advanced Research in Teaching and Education}

to measure the interventions' effectiveness. This is done by using a frequency distribution table and a four-point Likert scale. According to Acero and Leuterio (2006), the purpose of descriptive analysis is to determine the individual parts and units integrated into an internal system. It also determines the structure and composition that occurs as units within the larger structure which is very applicable in the study.

\subsubsection{Population and Locale of the Study}

There were ten grade 7 mathematics teachers at Baguio City National High School. Since the number was manageable, the researchers decided to survey the population. Hence, no sampling technique was used in this research. Therefore, the respondents of this study were the 10 grade 7 mathematics teachers of Baguio City National High School.

\subsubsection{Data Gathering Instrument}

For the first problem, the researchers used a checklist to identify what interventions were employed by the grade 7 mathematics teachers at BCNHS to assist in the improvement of numeracy skills of the students. The checklist was given to the 10 grade 7 mathematics teachers of BCNHS. Instructions were also included in the checklist to guide the respondents in accomplishing the questionnaire. The checklist was based on the reports accomplished by the teachers every grading on the different interventions teachers employ at Baguio City National High School to help struggling students in the different learning areas. There were a total of nine interventions enumerated in the checklist namely: conference with parents and student, remedial class, one-on-one tutorial, home visitation, provide supplementary materials and activities, peer tutorial, redo activities with low scores, refer to guidance counselors, and lessen items of activities.

To address the second objective, a second data gathering instrument was used, namely, fourpoint Likert scale. The respondents rated the interventions they employed according to the level of their effectiveness using a four-point likert scale with descriptive equivalences of highly effective, moderately effective, slightly effective, and not effective. The descriptive ratings of each descriptive equivalence are 4, 3, 2, and 1, respectively.

\subsubsection{Data Gathering Procedure}

The researchers asked permission from the school head through a written letter. After the request was approved and the letter signed, the researchers distributed the checklist to each of the 10 grade 7 mathematics teachers at Baguio City National High School to be answered. The respondents were told that the study was about the different interventions they used in aiding struggling students to improve their numeracy skills. They were assured confidentiality, and they provided informed consent. The respondents were then asked to recall all the interventions they used during the face-to-face classes as well as the virtual ones during this pandemic.

\subsubsection{Treatment of Data}

This part presents how the data gathered are treated according to the intentions of the research study. Moreover, this section discusses the statistical tools used in answering the research problems. 


\section{$4^{\text {th }}$ International Conference on Advanced Research in Teaching and Education}

Problem one focuses on the different interventions grade 7 mathematics teachers at Baguio City National High School use to help struggling students improve their numeracy skills. This was statistically treated using a frequency distribution table (FDT) since the purpose of this problem is to simply identify the interventions.

For the second problem, a four-point Likert scale was used to rate the different interventions according to their effectiveness as reflected on the scores and grades of students after the said intervention was employed. The range of values for each descriptive equivalence are as follows:

\begin{tabular}{llll}
\multicolumn{2}{c}{ Descriptive Rating } & Descriptive Equivalence & Symbol \\
\hline 1 & $3.26-4.00$ & Highly Effective & HE \\
2 & $2.51-3.25$ & Moderately Effective & ME \\
3 & $1.76-2.50$ & Slightly Effective & SE \\
4 & $1.00-1.75$ & Not Effective & NE
\end{tabular}

\subsection{Results and Discussion}

The researchers analyzed and presented the interventions utilized by Grade 7 Mathematics teachers in Baguio City National High School in order to determine the various interventions employed by the respondents.

The study also aimed to determine the effectiveness of the various interventions implemented by teachers in enhancing the numeracy skills of students who are underperforming in mathematics.

This section then presents and analyzes all the information gathered from the Grade 7 Mathematics teachers who served as the respondents of this undertaking.

\section{INTERVENTIONS EMPLOYED BY THE GRADE 7 TEACHERS.}

The first problem addressed in this study was the various interventions utilized by Grade 7 Mathematics teachers at Baguio City National High School to improve students' numeracy skills.

The interventions as well as the frequency of the various interventions employed by Grade 7 Mathematics teachers is shown in figure 1.

Figure 1. Interventions employed by Grade 7 Mathematics teachers

Figure 1 shows that there were seven interventions used by the teachers and these are as follows: Conference with parents and students, One - on - One Tutorial, Redo Activities with 


\section{$4^{\text {th }}$ International Conference on Advanced Research in Teaching and Education}

Low scores, Home Visitation, Provide Supplementary Materials and Activities, Lessen Items of Activities and Remedial Class.

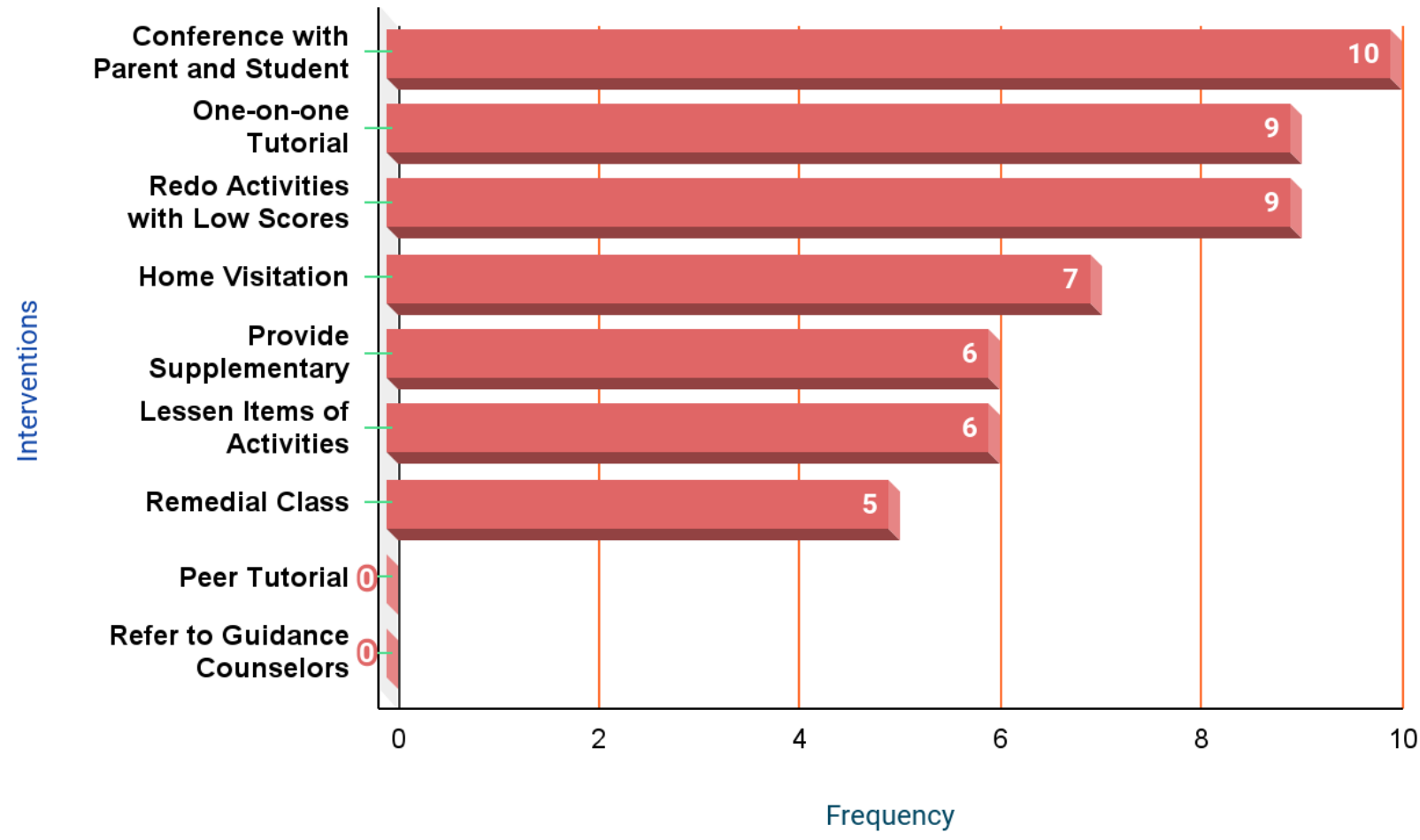

The data reveals that 10 out of 10 teachers used conferences with parents and students as an intervention to help students who were performing poorly in mathematics. This means that all of the teachers have decided to involve the parents in order to help their child with their difficulties in Mathematics. According to Seagreaves(2009), parent/student-teacher conferences provide benefits such as information sharing between teachers and parents to assist students in academic and social development, establishing a good relationship between the home and school, and facilitating face-to-face sessions in which teachers may clarify the meaning of grades and clear up any potential miscommunications. Students will value education more if their parents are actively involved in their children's academics, according to Hill and Taylor (2004), and they will tend to finish homework and other assignments more diligently. These were mainly the reasons why most of the teachers used this intervention.

As seen in the graph, one-on-one tutorials and redo activities with low results are the second most common interventions employed by teachers. This means that teachers adapt one-on-one tutorials to a student's specific needs in order to help them overcome their difficulties in the topic. Teachers also provide students the opportunity to recover from their low scores by asking them to redo their low-scoring activities. According to Cutler (2019), if the process is carefully handled, giving students the opportunity to redo examinations and assignments can help them continue to strive for mastery.

Home visitation is the third most common intervention used by 7 out of 10 teachers, according to the data. Following that, 6 out of 10 teachers employed supplemental activities and materials, as well as lessening the number of items in an activity. The least prevalent intervention is remedial lessons, which were employed by 5 out of 10 teachers. 


\section{$4^{\text {th }}$ International Conference on Advanced Research in Teaching and Education}

Furthermore, it is clear from the graph that none of the teachers employed peer tutoring or referred students to guidance counselors as interventions.

As reflected in the graph, most of the respondents used more than one intervention in catering the needs of students to improve their numeracy skills. This means that teachers implemented interventions that were tailored to the needs of the students. This also means that the teacher is exposed to students with a variety of learning requirements and challenges. This demonstrates that different approaches were employed by teachers for different types of students. According to Monks (2020), teachers can aid difficult pupils by understanding that certain children learn in various ways. Some pupils struggle with complex concepts, while others prefer to be challenged, and yet others prefer to learn in groups. Using a variety of teaching approaches can assist difficult pupils in discovering their preferred learning style and gaining confidence.

\section{INTERVENTIONS AND THEIR EFFECTIVENESS}

The second problem with the study is determining the effectiveness of the teachers' interventions. The researchers used Likert scale to evaluate the effectiveness of various techniques.

Table 1 below displays the effectiveness of each intervention used by teachers in developing students' numeracy skills.

Table 1. The interventions used by the teachers and their effectiveness.

\begin{tabular}{|c|c|c|c|}
\hline INTERVENTIONS & Effectivity & $\begin{array}{c}\text { Descriptive } \\
\text { Equivalence }\end{array}$ & Percentage \\
\hline Conference with Parents and Students & 3 & Moderately Effective & $75 \%$ \\
\hline One - on - One Tutorial & 3.89 & Highly Effective & $97.25 \%$ \\
\hline Redo Activities with Low Scores & 2.89 & Moderately Effective & $72.25 \%$ \\
\hline Home Visitation & 3 & Moderately Effective & $75 \%$ \\
\hline Provide Supplementary Materials and & 2.67 & Moderately Effective & $66.75 \%$ \\
\hline Activities & 3.17 & Highly Effective & $79.25 \%$ \\
\hline Ressen Items of Activities & 3.33 & Highly Effective & $83.25 \%$ \\
\hline Peerer Tutorial & NA & NA & NA \\
\hline NA & NA & NA \\
\hline
\end{tabular}




\section{$4^{\text {th }}$ International Conference on Advanced Research in Teaching and Education}

\begin{tabular}{llll}
\multicolumn{1}{l}{ Legend: } \\
Descriptive Rating & Descriptive Equivalence & Symbol \\
1 & $3.26-4.00$ & Highly Effective & HE \\
2 & $2.51-3.25$ & Moderately Effective & ME \\
3 & $1.76-2.50$ & Slightly Effective & SE \\
4 & $1.00-1.75$ & Not Effective & NE
\end{tabular}

As shown in table 1, the effectiveness of these interventions ranges from moderately effective to highly effective. The intervention parent-student conference, which was used by all of the teachers, was shown to be moderately effective, with a 75 percent effectiveness rate.

According to the data above, even though an equal number of teachers employed one-on-one tutorials and ordered students to retake activities with low scores, their effectiveness differs. With a 97.25 percent and 72.25 percent effectiveness rate, one-on-one tutorials are said to be highly effective, while redo activities with low scores are said to be moderately effective. Home visitation, the third most common intervention employed by teachers, has a 75 percent effectiveness rate, which is considered moderately effective. Following that, supplemental activities and materials were implemented, which have a 66.75 percent effectiveness rate, indicating that it is moderately effective. Moreover, lessened activities and remedial classes are both said to be highly effective, with rates of 79.25 percent and 83.25 percent, respectively.

As reflected, the effectiveness of these interventions were based on the number of teachers who used a distinct intervention that they employed. It was also discovered that, despite the fact that both interventions were used by an equal number of teachers, their effectiveness rates differed.

\section{Conclusion}

The Philippine's low level numeracy skills as reflected in the results of PISA in the last two years prompted teachers to employ different interventions to students who are performing poorly in mathematics. These interventions helped in improving numeracy skills of the said students. Amongst these, the most commonly used by the grade 7 mathematics teachers at Baguio City National High is conference with parent and student. However, the most effective intervention is one-on-one tutorial. Teachers are continuing to employ these interventions to improve students' numeracy skills. In the future, the researchers hope that this research will lead to better understanding of teachers as to what interventions might be used to help students who are performing poorly in mathematics to improve their numeracy skills. If we cannot help our students overcome this problem today, our whole country will suffer in different ways in the future. More innovative interventions are needed to make a significant difference in the level of numeracy skills of students. 


\section{$4^{\text {th }}$ International Conference on Advanced Research in Teaching and Education}

\section{Acknowledgements}

The researchers want to extend their warmest appreciation and sincere gratitude to everyone who helped and gave inspiration for the completion of this study.

To their respondents (the Mathematics teachers of BCNHS) for their great effort in giving the researchers sufficient information, for without them, this research will not be possible.

To their friends, relatives and loved ones who are always available at times of difficulties.

Above all, to the Almighty Creator whose always there to guide, understand and shower them with great strength, wit, patience and blessings, for without Him, they cannot reach this far.

\section{References}

\section{BOOK/S}

Acero, V. O., \& Leuterio, F. C. (2006). Methods of research (1st ed.). Rex Bookstore.

\section{Journal (Online sources)}

Akah and Danso (2018). "Examining the physical environment of ghanaian inclusive schools: How accessible, suitable and appropriate is such environment for inclusive education?" International Journal of Inclusive Education, pp. 188-208. Available: https://www.tandfonline.com/doi/abs/10.1080/13603116.2018.1427808

N.E, H., \& L.C, T. (2004). Parental school involvement and children's academic achievement: Pragmatics and issues. Current Directions in Psychological Science, 13(4). https://doi.org/10.1111/j.0963-7214.2004.00298.x

Identifying the essential ingredients to literacy and numeracy improvement: Teacher professional development and coaching, student textbooks, and structured teachers' guides. (2018). Identifying the Essential Ingredients to Literacy and Numeracy Improvement: Teacher Professional Development and Coaching, Student Textbooks, and Structured Teachers' Guides, 106, 324-336xs.

https://www.sciencedirect.com/science/article/pii/S0305750X18300287

Wardono, S. M. (2018). The analysis of mathematics literacy on PMRI learning with media schoology of junior high school students. Journal of Physics: Conference Series, 983, 012107. https://doi.org/10.1088/1742-6596/983/1/012107

\section{Online Sources}

Cristobal, L. (2015, August 6). International literacy association. Www.Literacyworldwide.Org. $\quad$ https://www.literacyworldwide.org/blog/literacynow/2015/08/06/literacy-in-the-philippines-the-stories-behind-thenumbers?fbclid=IwAR2eVhRM4S6V3pTTeQORZbZieqSQNTag4clBAxX2rZmtNnhzO $\underline{\mathrm{X} 1 \mathrm{eHXCSjPs}}$ 


\section{$4^{\text {th }}$ International Conference on Advanced Research in Teaching and Education}

Cutler, D. (2019, May 28). Tips for allowing test retakes. Edutopia. https://www.edutopia.org/article/tips-allowing-test-retakes

Seagreaves, P. (2009). The effectiveness of parent -teacher conferences for reporting student progress in a suburban Pennsylvania school district. ProQuest Dissertations and Theses. Widener University. Retrieved from https://search.proquest.com/dissertationstheses/effectiveness-parent-teacher-conferences/docview/305140965/se2? accountid $=13042$

Machera, R. P. (2017). Teaching Intervention Strategies that Enhance Learning in Higher Education. https://files.eric.ed.gov/fulltext/EJ1143759.pdf.

Matthew, L. (2019, October 15). Types of Classroom Interventions. The Edvocate. https://www.theedadvocate.org/types-of-classroom-interventions/.

Tips for Allowing Test Retakes. (2019, May 28). Edutopia.

https://www.edutopia.org/article/tips-allowing-test-retakes

Garoof \& Kurukkan (2015, August 18). https://files.eric.ed.gov/fulltext/ED560266.pdf.

Eric.Ed.Gov. https://files.eric.ed.gov/fulltext/ED560266.pdf

Walker, J. M. T., Wilkins, A. S., Dallaire, J. R., Sandler, H. M., \& Hoover-Dempsey, K. V. (2005). Parental Involvement: Model Revision through Scale Development. The Elementary School Journal, 106(2), 85-104. Available: https://doi.org/10.1086/499193 